\title{
CONFERENCE ON THE EFFECTS OF NUCLEAR WEAPONS
}

A WORLD conference of scientists to consider the effects of nuclear weapons was organized by the World Association of Parliamentarians for World Government and held at the County Hall, London, during August 3-5. The Right Hon. Clement Davies, president of the Association, opened the conference, and the Right Hon. Walter Elliot took the chair during the subsequent sessions.

Earl Russell opened the debate and moved his resolution urging Governments to acknowledge publicly that their purposes cannot be furthered by world war. He asked scientists to collect together the results of their investigations of the effects of nuclear warfare, and then see that they are clearly expressed in simple language and disseminated as widely as possible. Not only nuclear physicists, but also geneticists, meteorologists, authorities on soil and crops, and other experts will be needed in the investigations. Some of the work has been done already, but what is needed is a series of reports by internationally acknowledged authorities on the subjects concerned.

These reports would make it clear that a nuclear war would not bring victory to either side, but would probably create a planet destitute of life, except for a few mosses and fungi. If nuclear weapons are intended only as deterrents, and there is no intention of using them, then it would seem simpler and more economical to have the deadlock admitted and the impossibility of war acknowledged. War can no longer serve as an instrument of policy. We cannot wait to learn this by experience, because the experience would probably be that of universal death.

It is only the first steps that depend upon men of science as such. Their pronouncements will have to be taken up and clarified and emphasized by leaders of public opinion, who will have to make their weight felt by statesmen of East and West alike.

Another important sphere lying within the scope of science is the possible peaceful uses of atomic energy and of other seientific discoveries. The tendency of the general public to think of scientists as merchants of death must be combated, and it must be made clear that science could and would bring benefits to mankind as great as the disasters it has been rendering possible. If the world were liberated from fear of war, science could abolish poverty and raise the standard of living throughout the world, make deserts fertile, and ameliorate inclement climates.

Collective hatreds have darkened history since the dawn of organized society. They are about to cease, either because no one will be left alive to feel them, or because men will have learnt the elementary wisdom that only by overcoming collective hatred can the human race survive.

Earl Russell was followed in the debate by a number of distinguished speakers, including Prof. J. de Castro, Prof. M. L. Oliphant, Prof. E. Rabinowitch, Prof. A. J. Ayer, Prof. A. Topchiev, Lord Boyd Orr, Lord Beveridge, Prof. C. H. Waddington, Prof. R. W. Ditchburn and Prof. G. Boschi. They generally welcomed his proposals, in some cases with reservations, and stressed the dangers of nuclear weapons and the importance of developing the peaceful uses of nuclear energy.

On the second day, the scientists divided into three commissions to study the destructive potential of nuclear weapons and the hazards of the large-scale peaceful use of nuclear energy, the international control of atomic energy, and the individual and collective responsibility of the scientist. The other delegates debated the responsibility of Parliaments in the nuclear age.

The main task of the three commissions was to define more precisely their terms of reference and, where possible, to pose the questions that need to be answered. It is proposed that their reports be circulated to interested scientists all over the world with a request for comments, suggestions and details of scientific and technical investigations bearing upon them. These will be incorporated in a final report to be presented at another conference to be held in The Hague about a year hence.

The first commission examined the destructive potentials of nuclear weapons, the possible consequences of their massive use in war and in tests, and the possible harmful effects of the peaceful uses of atomic energy. It was agreed that its investigations should be carried out under the following headings : (a) physical destruction ; (b) effects on individuals ; (c) effects on animals and crops; (d) long-term genetical effects on human beings, animals and plants; (e) meteorological effects; $(f)$ effects of a rise in the general level of radioactivity in the atmosphere and the soil. Prof. J. Rotblat, of the Physics Department, Medical College of St. Bartholomew's Hospital, Charterhouse Square, London, E.C.1, was appointed secretary of the commission.

The second commission examined the technical problems of the supervision and control of the production and use of nuclear weapons with the view of enforcing their prohibition. A number of questions for further study were posed and classified under five headings: $(a)$ Detection of existing weapons and fissile materials : Can direct physical methods or other indirect methods be used for the detection of existing nuclear weapons and fissile materials, and if so, what are they? (b) Inspection of means of delivery of nuclear weapons: Can surprise attacks be made impossible by setting up a system of control of the means of delivery of such attacks, or of dangerous concentrations of air, naval or land forces for such an attack; for example, by establishing points of control in ports, road junctions, airfields, etc. ? (c) Control of mines and plants producing or employing fissile materials: Are the possibilities of the control of diversion from these plants of fissile materials affected by new scientific or technical developments, and are there methods by which the conversion for military uses of materials used in power plants can be made difficult or preventable? (d) Adaptation of controls to possible future developments : Can the control methods be made flexible enough to be adaptable to possible new developments such as new methods of initiation of thermo-nuclear reactions? (e) Nuclear weapon tests: How could nuclear tests be detected and how effective could be the cessation of such tests?

The commission said that the study of these questions would be greatly facilitated by closer international co-operation of scientists, and by the reduction of secrecy to a minimum. Dr. P. E. Hodgson, of the Physics Department, University College, London, W.C.1, was appointed secretary of the commission. 
The third commission examined the responsibility of scientists for the direction of their work, the uses to which it is put, and public knowledge of its implications. Dr. J. Bronowski, of the National Coal Board, Central Research Establishment, Stoke Orchard, Cheltenham, Glos, was appointed secretary of the commission.

The representative character of the conference was increased by the presence of a delegation from the U.S.S.R. comprising Academician A. Topchiev, professor of organic chemistry and general secretary of the Academy of Sciences of the U.S.S.R., Prof. C. A. Golounsky, director of the Institute of Criminology, University of Moscow, Prof. A. V. Kusin, a biochemist, and Prof. M. A. Markov, a theoretical physicist. The atmosphere of the discussions was cordial, and their conclusions unanimous.

The final day of the conference was devoted to the presentation and discussion of the reports of the three commissions. At its close, Earl Russell moved his resolution, which had been slightly modified as a result of the previous day's discussions: "Since in any future world war nuclear weapons will probably be employed and since such weapons threaten to bring immeasurable suffering for humanity, and material destruction, and possibly even the end of mankind, we urge, therefore, the governments of the world to realize and to acknowledge publicly, that their purposes cannot be furthered by world war; consequently we urge the full and open examination of the implications of recent scientific developments for humanity as a whole and the promotion of peaceful means for the settlement of all matters of international dispute". The resolution was carried unanimously.

P. E. HoDgson

\section{LONG ASHTON RESEARCH STATION \\ FIELD-DAY}

$\mathrm{F}^{\mathrm{T}}$ IELD.DAY was held at Long Ashton on July 20 in conjunction with the fifty-second annual general meeting of the governors, members and associates of the National Fruit and Cider Institute. Captain D. M. Wills, chairman of the governors, presided.

In reviewing the work of the Station during 1954, the director, Prof. T. Wallace, referred to the promising results obtained from foliage sprays and soil dressings of chelated compounds of iron in the control of lime-induced chlorosis of fruit trees. Although these compounds, derived from ethylenediamine tetra-acetic acid and related substances, are as yet expensive, he belizves that the residual effects obtained from a single application to calcareous soils make it likely that they can be developed to replace the present tedious technique of injecting pellets of ferrous sulphate into the trunks of affected trees. The chelates have been found to be photosensitive, and it is therefore necessary to water them well into the soil to prevent their breakdown at the soil surface.

In a brief account of the work of the Agricultural Research Council Unit of Plant Nutrition, Prof. Wallace recalled Dr. Nicholas's participation in experiments at the McCollum Pratt Institute which had shown molybdenum to be an essential constituent of the flavoprotein enzyme, nitrate reductase; he outlined investigations that are being made on other metallo-flavoproteins and on the valency changes of molybdenum within plants.

In a tour of the plantations, members saw threeyear-old trees of Cox's Orange Pippin and Bowden's Seedling that had been newly grassed-down in further studies of the effect of cover crops on the availability of soil nutrients and of their interaction with fertilizer treatments. Experiments made with cider-apples between 1946 and 1952 had shown that, compared with clean cultivation or annual cover-crops, a grass cover rapidly increased the potassium and phosphate status of the leaves while decreasing the nitrogen status; the effects on tree growth and fruit yield had not been readily determinable as the trees had been well established when the covers were sown.

Current trials with growth-substances were demonstrated. In the search for a compound suitable as a thinning-agent for heavy-bearing varieties of apple, naphthylacetamide has been tried for the first time in place of $\alpha$-naphthalene acetic acid (NAA), which had caused a loss of marketable crop in a number of consecutive years. Sprays of the amide applied four days after petal-fall gave variable results : they had drastically over-thinned test branches of Crawley Beauty when used at half the strength (50 p.p.m.) recommended in the United States, whereas they had failed to effect any thinning of Laxton's Superb even when used at $1 \frac{1}{2}$ times the recommended strength.

From the bareness of their branches it was possible to distinguish trees of Worcester Pearmain that had received sprays of $30-50$ p.p.m. $2: 4: 5$-TP $(2: 4: 5$-trichlorophenoxy propionic acid) in August 1953. Treatment had permitted apples of good quality to be har. vested fourteen days in advance of the normal crop, and had seemed likely to prove valuable to growers anxious to catch the early market. Damage to the treated trees had, however, become apparent early in 1954 , when their yield was only 25 per cent of that from untreated controls. The uncertainty attending empirical trials of growth-substances has served to emphasize the importance of the investigations that Long Ashton has been making since 1946 into the production of natural auxins during the development of apples and other fruits.

Members were also shown experiments to decide the best method of rooting gooseberry cuttings, and demonstrations were made of the frame-working and top-grafting of apples and of the spraying of dwarf pyramid apples by an automatic machine developed at the Research Station.

Laboratory exhibits illustrated the techniques used in determining the performance of spray machinery and materials: these included measurements of droplet size, of the distribution and persistence of various formulations of copper compounds on potato leaves, and of the residues of DDT and captan on apples and other fruits. A new method for the determination of small amounts of captan has shown a maximum deposit of 19 p.p.m. on fresh strawberries successfully sprayed in 1954 against Botrytis, using three applications at $0 \cdot 25$ per cent. While no taint had been apparent in the fresh fruit, a slight taint had developed during the storage of canned. fruit.

Other exhibits showed the use of radioactive tracers to follow the passage of systemic insecticides through bean and apple plants ; and the production of cankers on apple trees by inoculation with mycelium or spore suspensions of Gloeosporium perennans and the formulation of a BHC-DDT emulsion as a substitute for winter washes for apple trees. The need 